\title{
Correction to: Molecular imaging of advanced thyroid cancer: iodinated radiotracers and beyond
}

\author{
Prasanna Santhanam ${ }^{1}$ (]) Lilja B. Solnes ${ }^{2} \cdot$ Steven P. Rowe ${ }^{2}$
}

Published online: 12 December 2017

(c) Springer Science+Business Media, LLC, part of Springer Nature 2017

\section{Correction to: Med Oncol (2017) 34:189 \\ https://doi.org/10.1007/s12032-017-1051-x}

The original version of this article unfortunately contained a mistake. The middle name of the author Steven B. Rowe is incorrect. The corrected name is Steven P. Rowe.

The original article was corrected.

The original article can be found online at https://doi. org/10.1007/s12032-017-1051-x.

Prasanna Santhanam

Psantha1@jhmi.edu

1 Division of Endocrinology, Diabetes, and Metabolism, Department of Medicine, Johns Hopkins University School of Medicine, 1830 E. Monument St./Ste. 333, Baltimore, MD 21287, USA

2 Section of Nuclear Medicine, Department of Radiology and Radiological Science, Johns Hopkins University School of Medicine, Baltimore, MD 21287, USA 